\title{
AVALIAÇÃO DO USO DA TERRA NAS ÁREAS DE PRESERVAÇ̃̃o PERMANENTE HÍDRICAS DO MUNICÍPIO DE MACEIÓ - ALAGOAS - BRASIL
}

\author{
Sinval Autran Mendes Guimarães Júnior \\ Universidade Federal de Alagoas, Instituto de Geografia, Desenvolvimento e Meio Ambiente, \\ Maceió, AL, Brasil \\ sinval.autran@igdema.ufal.br
}

Silvana Quintella Cavalcanti Calheiros

Universidade Federal de Alagoas, Pós-Graduação em Geografia, Maceió, AL, Brasil

silvanaq@igdema.ufal.br

\begin{abstract}
RESUMO - A pesquisa teve como objetivo avaliar o uso da terra nas Áreas de Preservação Permanente Hídricas - APPHs do município de Maceió - Alagoas - Brasil. Maceió vem sendo alvo, nos últimos 30 anos de um surto desenvolvimentista que tem agredido violentamente o seu patrimônio natural, propiciando o surgimento e a proliferação de áreas sujeitas a deslizamentos/desmoronamentos e enchentes, parte destas ocorrendo em APPs. A metodologia utilizada nesta pesquisa teve como base a utilização do Sistema de Análise Geo-Ambiental (SAGA/UFRJ) a partir da leitura e interpretação dos Códigos Florestais Brasileiro de 1965 e 2012, na qual foram gerados os mapas na escala 1:50.000 com resolução espacial de $10 \mathrm{~m}$, referente ao uso da terra e as APPHs do município de Maceió. A sobreposição desses mapas permitiu constatar o uso da terra nas APPHs, com a geração então, do mapa de uso da terra nas APPHs, tendo, a cana-de-açúcar, as pastagens/campos, a urbanização e o cultivo do coco-da-baía como sendo os principais elementos de ocupação/uso sobre as APPHs, configurando assim, um cenário ambiental altamente impactante. Tal condição aponta para urgência de um planejamento ambiental adequado às suas condições locais, a partir de medidas voltadas para sua desapropriação e recuperação/revitalização.
\end{abstract}

Palavras-chave: Geoprocessamento; Uso da terra; Legislação ambiental.

\section{AVALIAÇÃO DO USO DA TERRA NAS ÁREAS DE PRESERVAÇÃO PERMANENTE HÍDRICAS DO MUNICÍPIO DE MACEIÓ - ALAGOAS - BRASIL}

\begin{abstract}
The research had as intention to evaluate the land use in the Permanent Water Preservation Areas - APPHs of the municipality of Maceió - Alagoas - Brazil. Maceió has been target in the last 30 years of a developmental outbreak that has violently attacked its natural patrimony, propitiating the emergence and proliferation of lands subject to landslides and floods, part of these occurring in APPs. The methodology used in this research was based on the use of the GeoEnvironmental Analysis System (SAGA / UFRJ) from the reading and interpretation of the Brazilian Forest Codes of 1965 and 2012, in which maps were generated in the 1: 50,000 scale with resolution of $10 \mathrm{~m}$, related to land use and the APPHs of the municipality of Maceió. The overlap of these maps made it possible to verify the land use in the APPHs, with the generation of the land use map in the APPHs, with sugarcane, pastures / fields, urbanization and coconut tree cultivation as the main occupation / use elements on the APPHs, thus configuring a highly impacting environmental scenery. Such condition points to the urgency of an environmental planning appropriate to its local conditions, based on measures directed at its expropriation and recovery / revitalization.
\end{abstract}

Keywords: Geoprocessing; Landuse; Environmental legislation.

\section{INTRODUÇÃO}

Ao longo de quatro séculos a área que compreende atualmente o território alagoano vem sofrendo transformações decorrentes da exploração predatória dos seus recursos naturais. A retirada do pau Brasil, seguida da derrubada da floresta primitiva para a implantação da pecuária e do cultivo da cana-de-açúcar, podem ser consideradas as principais formas de exploração, que se prolonga até 
os dias atuais (LIMA, 1992; ANDRADE, 1997). Até o início do século XVI, 30,31\% da cobertura vegetal original de Alagoas, eram formadas por florestas ombrófilas (Mata Atlântica) que foram reduzidas em apenas $1,85 \%$ no final do século XX (ASSIS, 2000).

O Código Florestal Brasileiro (Lei n. 4.771, de 15 de setembro de 1965) e Novo Código Florestal Brasileiro (Lei $n^{0} 12.651$, de 25 de maio de 2012), a exemplo de outros documentos legais, como as Resoluções do Conselho Nacional do Meio Ambiente - Conama n. 004/1985 e n.303/2002 e o Código Municipal de Meio Ambiente de Maceió (Lei n. 4.548, de 21 de novembro de 1996 proíbem a ocupação/uso do solo em Áreas de Preservação Permanente (APP). Entretanto, devido à tradição de uso intensivo do solo no passado e as dificuldades de imposição da legislação ambiental, pouco se tem feito para verificar essa condição, já que a sua manutenção, em especial da vegetação de natural das mesmas é essencial para a melhoria da qualidade do meio ambiente.

As técnicas de geoprocessamento e sensoriamento remoto são ferramentas importantes para o planejamento territorial, já que podem ser aplicadas na obtenção de dados e informações a serem utilizados em zoneamentos ambientais e planos diretores. O desenvolvimento marcante destas geotecnologias tem disponibilizado uma série de ferramentas que auxiliam sobremaneira na investigação da ocupação/uso do solo nas APP, como também em outras áreas de interesse ambiental, como por exemplo, unidade de conservação.

O município de Maceió vem sendo alvo, nos últimos 30 anos, de um surto desenvolvimentista que tem agredido violentamente seu patrimônio natural e, de forma grave, sua população, principalmente a de baixa renda que, reprimida por interesses poderosos, vê-se obrigada a ocupar áreas cada vez mais distantes do trabalho. Este fato tem propiciado o surgimento e a proliferação de áreas sujeitas a deslizamentos/desmoronamentos e enchentes, parte destas ocorrendo em APPs, especialmente, nas APPHs. Sendo assim, esse município foi escolhido para investigação, face as suas características de ocupação/uso desordenada do seu território, que induziram a um desafio maior na avaliação da eficácia da geotecnologia utilizada neste estudo.

Partindo destas premissas, a pesquisa teve como objetivo avaliar o uso da terra nas APP do município de Maceió. A metodologia utilizada nesta pesquisa teve como base a utilização do Sistema de Análise Geo-Ambiental, da Universidade Federal do Rio de Janeiro (SAGA/UFRJ) a partir da leitura e interpretação Novo Código Florestal Brasileiro, na qual foram gerados os mapas de uso da terra e de APPHs (margens de cursos d'águas, reservatórios naturais/artificiais e nascentes), na escala 1:50.000, com resolução espacial de 10m. A sobreposição desses mapas permitiu constatar o uso da terra nas APPHs.

A avaliação o uso da terra nas APPHs (margens de cursos d'águas, reservatórios/naturais e nascentes) do município de Maceió foram desenvolvidos por meio da obtenção e geração de dados e informações espaciais e não-espaciais, obedecendo duas etapas. Uma voltada para a obtenção de dados e informações, e a outra para a criação de um modelo digital do ambiente por meio da geração de mapas digitais temáticos, na qual foram executadas assinaturas e planimetrias ambientais. Na criação do modelo digital do ambiente foram utilizados dados e informações pertencentes ao acervo do Laboratório de Geoprocessamento Aplicado, do Instituto de Geografia, Desenvolvimento e Meio Ambiente, da Universidade Federal de Alagoas (LGA-IGDema-Ufal). Este foi orientado ainda pela legislação ambiental, em especial, no que diz respeito à definição de APP, segundo o Novo Código Florestal Brasileiro (Lei $\mathrm{n}^{\mathrm{o}}$ 12.651, de 25 de maio de 2012).

\section{ÁREA DE ESTUDO}

O município de Maceió está localizado (Figura 1) na parte central do litoral do estado de Alagoas, entre 8924000 a $8966000 \mathrm{mN}$ e 190000 a 220000 mE (Zona.fuso SC.25). 
Figura 1. Localização do município de Maceió, Alagoas - Brasil

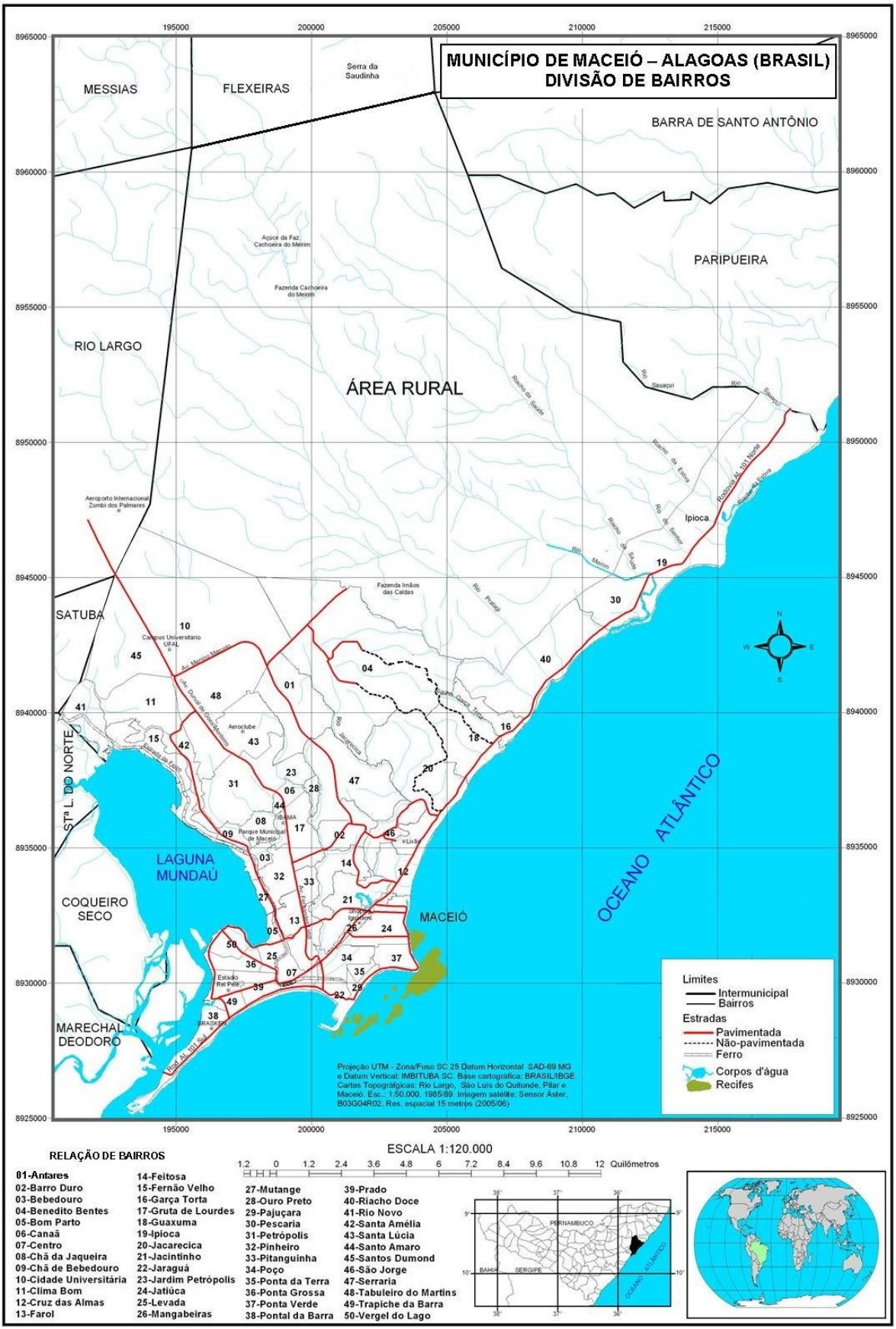

Fonte: Maceió (1998; ca. 2000) e IBGE (2011).

Segundo dados do Ibge de 2010, o município de Maceió abrange uma área de 510,655 km², o que correspondendo a $1,83 \%$ do território alagoano. A população em 2010 era de 932.748 habitantes, o que lhe conferia uma densidade demográfica de $1.826,57 \mathrm{hab} / \mathrm{km}^{2}$ (BRASIL, 2011). O município integra com outros dez municípios, a Região Metropolitana de Maceió, totalizando quase de 1.200.000 habitantes. O município é o mais populoso de Alagoas e o $17^{\circ}$ do Brasil e o $73^{\circ}$ do continente americano. Maceió está inserido na Mesorregião Geográfica do Leste Alagoano e na Microrregião Geográfica homonímia, localizada na Região Nordeste do Brasil (BRASIL, 2014). A sua área urbana e de expansão é formada atualmente por cinquenta bairros Maceió (MACEIÓ, 1998; ca. 2000).

O município de Maceió esta sob influência de clima úmido e subúmido úmido. O clima atuante na cidade de Maceió, segundo a classificação de Thornthwaite é o quente, com índice de umidade 
efetiva variando de: o úmido [40 a 60] e [20 a 40] e subúmido úmido [0 a 20] com temperatura média anual de $25^{\circ}$ até $29^{\circ} \mathrm{C}$ (FONSECA e AZEVEDO, 1983; ALAGOAS, 1999). A estrutura geológica do município é formada por depósitos areno-argilosos e argilosos da Formação Barreiras (Bacia Sedimentar Alagoas), aflorando ainda rochas cretáceas das Formações: Coqueiro Seco, Penedo, Ponta Verde, Poção, entre outras (GAVA et. al., 1983; DANTAS e CALHEIROS, 1986; FEIJÓ, 1994). O seu relevo de Maceió na sua maioria se apresenta plano e suavemente ondulado, representados respectivamente pela Planície Litorânea e o Planalto Sedimentar dos Tabuleiros (NOU et al., 1983). Os solos que ocorrem em maior extensão no município de Maceió são os Argissolos Amarelos, Vermelhos, Vermelho-Amarelos e Acinzentados e os Latossolos Amarelos, Vermelhos e Vermelho-Amarelos. Em menor extensão, ocorrem os Neossolos Quartzarênicos, os Espodossolos Humilúvicos e Ferrihumilúvicos, os Gleissolos Melânicos e os Neossolos Flúvicos (WAKE et al., 1983; ALAGOAS, 2012).

A cobertura vegetal do município de Maceió se encontra bastante descaracterizada. De forma descontínua ocorre nas encostas remanescentes de Floresta Ombrófila. Em menor extensão, no reverso tabuliforme das falésias ocorrem Áreas de Transição Fitoecológica (Ecótono Floresta Estacional-Cerrado) e na planície litorânea, ocorrem Áreas as Formações Pioneiras sob influência Marinha (restingas) e Flúvio-Marinha (manguezais). (GONÇALVES e ORLANDI, 1983; ASSIS, 2000). As principais bacias hidrográficas que drenam o município de Maceió estão inseridas na Vertente Atlântica ou Oriental. Os cursos d'águas dessa vertente são formados pelos rios: Meirim- Saúde, Prataji, Estiva, Sapucaí e os riachos Graça Torta, Guaxuma, Jacarecica, Águas Férreas, Reginaldo, Silva-Petropólis. Todos estes cursos d'águas possuem regime permanente de padrão de drenagem dendrítica com escoamento exorreico (ALAGOAS, 1979).

\section{REVISÃO DA LITERATURA}

A pesquisa baseou-se na abordagem sistêmica dirigida ao estudo da região e da paisagem numa perspectiva de escala geográfica local.

O conceito de região teve como referência a abordagem neopositivista do Método Regional e da Nova Geografia (CORRÊA, 2000). No primeiro, o estudo se apoiou na diferenciação de áreas vista como a integração de fenômenos heterogêneos em uma dada porção da superfície terrestre, e não vista apenas pelas relações entre o homem e a natureza, tendo em vista que este método focaliza assim o estudo de áreas, erigindo não uma relação causal ou a paisagem regional, mas a sua diferenciação de forma isolada como objeto da geografia. No segundo, o estudo se apoiou no relacionamento das leis ou das regularidades empíricas sob a forma de padrões espaciais, considerando a região como um caso particular de classificação, tal como se procede nas ciências naturais (CORRÊA, 2000). Assim, a região faz referência a uma porção de um território determinada por certas características comuns ou circunstâncias especiais, ou seja, uma divisão territorial geralmente normatizada e definida por questões geográficas, histórico-culturais e socioeconômicas, que conta com várias subdivisões. No entanto, nesta pesquisa, que trata do uso da terra nas APPHs e sua própria definição é resultante do território normatizado, ou seja, definidos por leis (SANTOS, 1996).

O conceito de paisagem a partir de uma abordagem sistêmica procura relacionar os fatores bióticos e abióticos num processo dinâmico interagindo entre si. Para compreendermos a paisagem é necessário entender o processo interativo dos fatores que modelam o meio, na qual a ação antrópica atua intensificando o processo de construção e desconstrução da paisagem. Dentro dessa analise a paisagem pode ser conceituada, em determinada amostra do espaço, como "[...] o resultado da combinação dinâmica, portanto instável, de elementos físicos, biológicos e antrópicos que, reagindo dialeticamente uns sobre os outros, fazem da paisagem um conjunto único e indissociável em perpétua evolução" (BERTRAND, 1972, p.141). Em sua Geografia Física Global, Bertrand conceitua geossistema como um tipo de sistema aberto, 
hierarquicamente organizado, formado pela combinação dinâmica e dialética de um potencial ecológico (geomorfologia, clima, hidrologia), de uma condição de exploração biológica natural (vegetação, solo, fauna) e das atividades ditas antrópicas. Partindo dessa abordagem, o autor propôs a adoção de escalas espaciais diferentes - em ordem decrescente são elas a zona, o domínio, a região, o geossistema, o geofácies e o geotopo, estes dois últimos classificados a partir de critérios biogeográficos e antrópicos (SALES, 2004, p. 130).

Para Casseti (1995) o homem ao se apropriar da natureza ele a transforma, pode assim, trazer com isso alterações significativas na exploração biológica, gerando gradativamente modificações no potencial ecológico. Temos assim a sociedade como elemento produtor e modificador da paisagem trazendo disparidades ao meio natural, ou seja, ocasionando tensores para a degradação ambiental.

A pesquisa buscou avaliar também como o uso da terra nas APPHs provoca modificações na paisagem. Nesse sentido, sua manutenção é imprescindível, já que elas representam a proteção do solo contra os processos erosivos, podendo este ainda ser ampliado por outros fatores ambientais. Esses fatores desencadeadores dos processos erosivos provocados pelo uso da terra nas APPHs podem ser então, resposta a diferentes ações ou imposições antrópicas, geralmente indicadas por inúmeras intervenções, na sua maioria indisciplinares e consequentemente causadoras de impactos ambientais. Esses são fatores causais que induzem a processos erosivos nas APPHs, que em função das propriedades físicas dos solos utilizados ou sem cobertura vegetal poderão ser mais ou menos vulneráveis à erosão nesses ambientes.

Nesse sentido, o sensoriamento remoto e o geoprocessamento são técnicas que se mostram viável e confiável no tocante a automatização de procedimentos técnico-operacionais e metodológicos voltados para elaboração de diagnósticos e prognósticos ambientais. Essas ações têm auxiliado ao poder público (municipal, estadual e federal) na redução das deficiências relativas ao cumprimento da legislação ambiental no tocante a manutenção das APPs. Conforme a funcionalidade e a eficácia desses procedimentos, integrada a dados produzidos pelas imagens de satélite, sobretudo as de alta resolução espacial, podem produzir diagnósticos e fortalecer as ações ambientais de monitoramento como suporte para os instrumentos jurídicos de controle e fiscalização ambiental, em especial, as APPs (NASCIMENTO, 2006).

Segundo Zanata e Leal (2009) foi a partir da década de 1930 começam os prenúncios sobre planejamento ambiental no Brasil, quando foram modelados os planejamentos de recursos hídricos e gestão de bacias hidrográficas e, consequentemente, criou-se a constituição do Código de Águas, do Código Florestal e da Lei de Proteção à Fauna. O primeiro Código Florestal Brasileiro foi instituído pelo Decreto $\mathrm{n}^{\circ}$ 23.793, de 23 de janeiro de 1934, trinta e um anos depois revogado pela Lei 4.771/65, que estabeleceu o Código Florestal, que permaneceu em vigência até 2012, quando foi aprovado o Novo Código Florestal Brasileiro (Lei $\mathrm{n}^{\circ}$ 12.651, de 25 de maio de 2012). Este novo Código a exemplo do anterior estabelece limites de uso da propriedade, que deve respeitar a vegetação existente na terra, considerada bem de interesse comum a todos os habitantes do Brasil, como por exemplo, as chamadas Áreas de Preservação Permanente (APP).

O conceito de APPs presente no Código Florestal Brasileiro Brasileiro (Lei $\mathrm{n}^{\mathrm{o}}$ 12.651, de 25 de maio de 2012), emerge do reconhecimento da importância da manutenção da vegetação de determinados biotópos, as quais ocupam ou utilizam porções particulares de uma propriedade, não apenas para os legítimos proprietários que possuem terras nesses, mas, em cadeia, também para os demais proprietários de outras terras de uma mesma comunidade, de comunidades vizinhas, e, finalmente, para todos os membros da sociedade.

O Código Florestal Brasileiro (Lei n. 4.771, de 15 de setembro de 1965) e Novo Código Florestal Brasileiro (Lei ${ }^{\circ}$ 12.651, de 25 de maio de 2012), a exemplo de outros documentos legais, como as Resoluções do Conselho Nacional do Meio Ambiente - Conama n. 004/1985 e 
n.303/2002 define as APP como sendo aqueles espaços protegidos e cobertos por vegetação nativa, que tem como função ambiental: preservar os recursos hídricos, a paisagem, a estabilidade geológica, a biodiversidade, o fluxo gênico de fauna e flora, a proteção do solo e assegurar o bem-estar das populações humanas. Segundo esse mesmo código e as resoluções brasileiras são consideradas como APPs: a) Margens de rios - ao longo dos rios ou de qualquer curso d'água desde o seu nível mais alto em faixa marginal mínima em função da sua largura; b) ao redor de lagoas, lagos ou reservatórios naturais e artificiais; c) nas nascentes de olhos d'água; d) no topo de morros, montes, montanhas e serras; e) nas encostas com inclinação superior a $45^{\circ}$ graus, e) Restingas - fixadoras de dunas ou estabilizadoras de mangues, em faixa mínima de 300 metros, a contar da linha de preamar máxima, f) Manguezais - em toda sua extensão; Dunas - com vegetação fixadora; g) Tabuleiro ou chapadas - nas suas bordas, a partir da linha de ruptura do relevo, em faixa nunca inferior a 100 metros em projeções horizontais; $h$ ) Altitude superior a 1.800 (mil e oitocentos) metros, qualquer que seja a vegetação; i) Áreas metropolitanas - quando da existência de vegetação natural se encontrar em seu clímax ou estágios médios e avançados de regeneração.

Além do exposto acima são considerados ainda, como APPs, de acordo Lei Municipal $\mathrm{N}^{\mathrm{o}}$ 4.548, de 21 de novembro de 1996 que institui o Código Municipal de Meio Ambiente no seu artigo $66^{\circ}$, incisos I ao VI: a) o Parque Municipal de Maceió; b) a piscina natural da Pajuçara; c) os recifes e corais do litoral de Maceió; d) a vegetação do entorno da lagoa Mundaú; e) as ilhas da lagoa Mundaú e f) as coleções florísticas remanescentes da Mata Atlântica em todo território do município de Maceió (MACEIÒ, 1996).

As APPs representam assim, segundo Lima e Zakia (2004) uma porção do espaço físico que não deve ser ocupada e/ou alterada, já que estas têm importância fundamental para a manutenção dos cursos de água, pois: auxiliam na infiltração de água no solo, facilitando o abastecimento do lençol freático; mantêm a qualidade da água, dificultando o escoamento superficial de partículas e sedimentos que causam poluição e assoreiam os recursos hídricos; fornecem sombra, mantendo a estabilidade térmica da água; impedem o impacto direto da chuva no solo, minimizando processos erosivos; servem de abrigo e alimento para grande parte da fauna aquática.

No entanto, segundo Boin (2005), chama atenção, que mesmo após a aprovação do Código Florestal, o uso da terra nas APPs continua ocorrendo de forma rápida e a busca pela produção de alimentos, água potável mais acessível, madeira e combustível foram atrativos para essa condição. O não cumprimento deste código, entretanto, colocou e tem colocado em risco e, em alguns casos, acarretando em danos para biodiversidade e qualidade dos recursos hídricos. A presença de APPs implica teoricamente, nem sempre na prática, o impedimento legal de ações antrópicas que comprometam a exploração sustentável dos recursos naturais. O comprometimento das fontes e mananciais de água, em quantidade e qualidade, está associado às ações antrópicas que quase sempre não respeitam a capacidade de suporte da natureza (MARTINS, 2008).

Como explicitado anteriormente, as APPs são resguardadas por lei e foram assim criadas para proteger o ambiente natural, devendo estar cobertas com a vegetação original, não sendo áreas apropriadas para o uso da terra, a não ser que sejam consideradas de interesse do estado. A cobertura vegetal nas APP ajuda a atenuar os efeitos erosivos e a lixiviação dos solos, contribuindo também para a regularização do fluxo hídrico, redução do assoreamento dos cursos d'água e reservatórios, e trazendo também benefícios para a fauna (COSTA et al., 1996). Embora a legislação ambiental brasileira seja considerada bastante ampla, alguns fatores têm contribuído para torná-la pouco ágil, dentre esses, destaca-se a deficiência em meios e materiais para apurar com vigor as agressões ambientais. Diante desse fato, as metodologias possíveis de serem executadas por meio do geoprocessamento tornam-se alternativas viáveis para reduzir de maneira significativa as deficiências relativas ao cumprimento das leis pertinentes (NASCIMENTO, 2004; 2005).

Desta forma, tendo como referência a literatura anteriormente comentada, buscou-se conhecer as 
condições ambientais vigentes no município de Maceió, visando definir e analisar suas diversas incompatibilidades quanto à ocupação/uso nas Áreas de Preservação Permanente (APPs).

\section{METODOLOGIA}

A pesquisa foi fundamentada no uso das geotecnologias, tendo como referência a utilização de técnicas de geoprocessamento aplicadas. Essas quando utilizadas sobre uma base de dados ambientais vem se mostrando uma alternativa cada vez mais viável e confiável no tocante a automatização de metodologias para aquisição e monitoramento ambiental, reduzindo consideravelmente às deficiências relativas ao cumprimento da legislação quanto à manutenção das APPs (NASCIMENTO, 2004; RIBEIRO et al., 2005). Por ser uma tecnologia que apresenta um custo relativamente baixo, o geoprocessamento está sendo utilizado em países de grande dimensão territorial e com poucas informações em escalas adequadas, já que esses estudos mostraram-se de grande eficiência para tomada de decisões sobre o território (FLORENZANO, 2002).

O geoprocessamento consiste em um conjunto de técnicas computacionais que opera sobre bases de dados georreferenciados que os transformar em informação relevante, na qual os dados são considerados os registros de ocorrências e a informação, o acréscimo de conhecimento. (XAVIER DA SILVA, 2001). O geoprocessamento é considerado desta forma, como uma ferramenta poderosa que utiliza técnicas matemáticas e computacionais para a obtenção, geração e manipulação de dados e informações geográficas e tem sido cada vez mais utilizado para a análise dos recursos naturais. Essa ferramenta é especialmente útil para países de grandes dimensões e com deficiência de dados e informações em escalas adequadas, pois apresenta um grande potencial para a tomada de decisões sobre planejamento urbano e ambiental, principalmente por ser uma tecnologia que apresenta um custo relativamente baixo (ASSAD e SANO, 1998; FLORENZANO, 2002).

Assim, visando avaliar a ocupação/uso atual nas APPHs (margens de cursos d'águas, reservatórios/naturais e nascentes) do município de Maceió, a pesquisa foi desenvolvida por meio da coleta e produção de dados e informações espaciais e não-espaciais, obedecendo duas seguintes etapas: a de pré-geoprocessamento, que diz respeito à obtenção de dados e informações, e a de geoprocessamento, que se refere à geração dos mapas digitais temáticos, com a execução de assinaturas e planimetrias ambientais.

A etapa de pré-geoprocessamento consistiu na obtenção de dados e informações complementares e auxiliares que consistiu em consulta a fontes: bibliográficas (legislação ambiental, trabalhos anteriores dados estatísticos, aspectos de localização, do ambiente físiconatural e antrópico da área de estudo); cartográficos (cartas topográficas, geológicas, mapas temáticos, mapas digitais geoprocessados), aerofotográficos (fotografias aéreas) e de sensoriamento remoto (imagens de satélite).

A etapa de geoprocessamento consistiu na elaboração e sobreposição dos mapas de uso da terra do município de Maceió e das APPHs. Para isso, foram utilizadas técnicas de geoprocessamento aplicadas do Sistema de Análise Geo-Ambiental da Universidade Federal do Rio de Janeiro (SAGA/UFRJ) referentes aos módulos visualiza (módulo de visualização de um mapa), Criar RS2 (módulo de criação de arquivos raster saga), Combinar (algoritmo de combinação de dois mapas).

Os planos de informações ou mapas digitais foram gerados com base em coleta de dados espaciais convencionais, digitais, leitura de documentos cartográficos, interpretações de fotografias aéreas e imagens de satélite. Estes mapas digitais foram obtidos a partir dos formatos digitais das cartas topográficas da Região Nordeste do Brasil do IBGE, escala 1: 50.000, com equidistância entre curvas de nível igual a $20 \mathrm{~m}$, projeção Universal Transversa de Mercator, 
referentes às Folhas: Rio Largo, São Luís do Quitunde, Pilar e Maceió, editadas em 1985.

A interpretação visual da imagem espectral do Satélite Landsat 5 - Land Remote Sensing Satellite, Sensor TM com resolução geométrica de 30 metros (ANEXO A), permitiu por meio de uma chave de identificação definida a partir dos elementos mais visíveis como: tonalidade/cor, textura, forma, sombra, altura, padrão e localização. Este procedimento teve como referência os trabalhos desenvolvidos por Garcia (1986), Pereira, et al., (1989); Florenzano (2002) e Novo (2010), os elementos como sombra e altura foram desconsiderados visto que a imagens não apresenta muita cobertura de nuvens, bem como, áreas urbanizadas com a presença de prédios do tipo "arranha-céus".

De posse dessa chave de interpretação foi gerado o mapa de uso da terra do município de Maceió - 2011 (APÊNDICE A) a partir da edição dos dados na imagem no Módulo Criar RS2. O mapa de APP margens de cursos d'águas, reservatórios/naturais e nascentes (APÊNDICE B) foi gerado no Módulo Visualiza com a criação de buffers, conforme definido pela legislação ambiental: margens de cursos d'águas (30 metros), reservatórios/naturais e nascentes (50 metros). Visando o acabamento final dos mapas, esse módulo foi usado ainda para exportação de mapas no formato raster (.rs2) para bitmap (.bmp). O mapa de de uso da terra do município de Maceió - 2011 x APP (APÊNDICE C) foi gerado no Módulo Combinar na qual foi realizada a sobreposição os mapas acima mencionados. A quantificação das categorias de uso da terra nas APPHs foi realizada no Módulo Assinatura com obtenção de áreas suas áreas em hectares (ha) e transformadas em quilômetros quadrados $\left(\mathrm{km}^{2}\right)$.

\section{RESULTADOS E DISCUSSÃO}

O Mapa de Uso da Terra/Cobertura Vegetal (APÊNDICE A) destaca a ocorrência de quatros categorias: cana-de-açúcar, campo/pasto, urbano e o coco-da-baía. Essas categorias representam o conjunto das atividades antrópicas com 330,76 $\mathrm{km}^{2}(69,36 \%)$ do município de Maceió.

Quanto à cobertura vegetal, cinco categorias foram planimetradas: floresta ombrófila (remanescentes), vegetação em estágio de sucessão natural e as formações pioneiras (marinhas, flúvio-marinha e fluvial). Essas categorias representam o conjunto das áreas naturais com $146,01 \mathrm{~km}^{2}$, o que corresponde a 30,64\% da extensão territorial do município de Maceió

O Mapa de Áreas de Preservação Permanente Hídricas (APÊNDICE B) do município de Maceió apresenta $107,70 \mathrm{~km}^{2}$, o que equivale a $24,86 \%$ da sua área total que é de $433,23 \mathrm{~km}^{2}$, desconsiderando a área da laguna Mundaú e dos canais interlagunares.

O Mapa de Uso da Terra/Cobertura Vegetal nas Áreas de Preservação Permanente Hídricas (APÊNDICE C), mostra que o cultivo da cana-de-açúcar (Figura 2) é o uso mais marcante com $51,81 \mathrm{~km}^{2}(48,11 \%)$, seguida de pastagens/campos (Figura 3) com 39,35 $\mathrm{km}^{2}(36,54 \%)$, totalizando $91,16 \mathrm{~km}^{2}$, o que corresponde a $84,65 \%$ do total das APP. O sítio urbano de Maceió (Figura 4) ocupa 12,24 km² (11,37\%) e a cultura do coco-da-baía (Figura 5) utiliza 4,29 km² $(3,98 \%)$.

A manutenção das APPHs representa a proteção do solo contra os processos erosivos, considerando que é preciso uma densa cobertura vegetal e ocupações adequadas para evitar a erodibilidade do solo. Uma densa vegetação favorece entre propicia outros: a) maior proteção contra o impacto das gotas de chuva sobre o solo, não havendo o desprendimento imediato das partículas do solo; b) maior capacidade de infiltração, através das raízes, diminuindo os efeitos erosivos de transporte e formações erosivas; c) melhoria as condições físicas, químicas e biológicas da estrutura do solo, pela adição de matéria orgânica, aumentando sua capacidade de retenção de água e arejamento. Nesses casos, a cobertura vegetativa ou edáfica consistem nas práticas conservacionistas mais adequadas, fazendo aumentar a resistência do solo ou diminuir 
a ação dos processos erosivos sobre as APPHs.

$\mathrm{O}$ rápido processo de erosão do solo nas $\mathrm{APPHs}$ provocados pela ocupação e uso pode ser ampliando por um conjunto de fatores (chuva, escoamento, solo, encosta, cobertura vegetal e prática conservacionista), se apresentam segundo Goes (1990), em três grupos: a) energia representada pela erosividade da chuva, em função da sua intensidade, duração e também, pelas condições morfométricas do relevo; b) resistência, indicada pela erodibilidade do solo, ou seja, pela sua resistência ao desprendimento dos sedimentos e transporte, pela capacidade de infiltração e finalmente pelo tipo de manejo do solo (uso de práticas conservacionistas); c) proteção do solo, em virtude da sua ocupação e manejo, como a densidade populacional (adensamentos suburbanos e urbanos sem planejamento), cobertura vegetal (fraca densidade) e manejo do solo (com ou sem práticas).

Figura 2. APPs nascentes utilizadas por canade- açúcar. Próximo a usina Cachoeira do Meirim - Mun. de Maceió, Alagoas - Brasil, jan. de 2004.

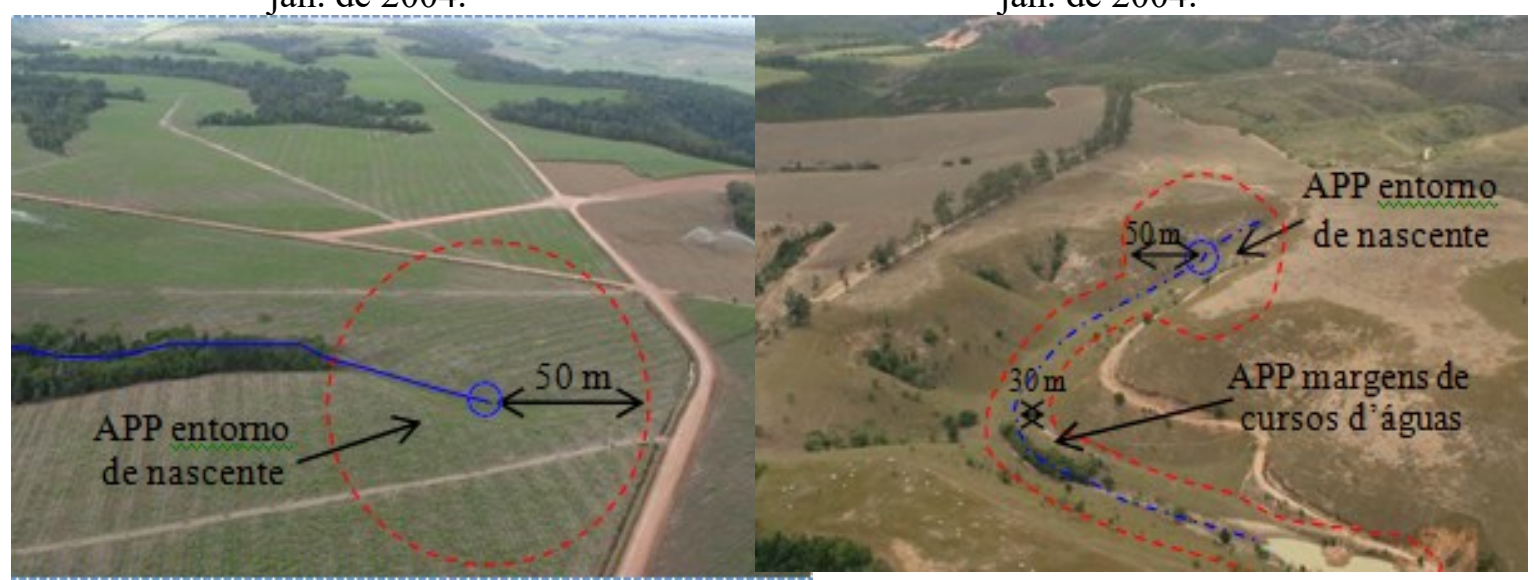

Fonte: Gersrad - Ufal (2003).

Figura 4. APPs margens de reservatório natural urbanizadas. Distrito Industrial Luiz Cavalcanti - Mun. de Maceió, Alagoas Brasil, jan. de 2004.

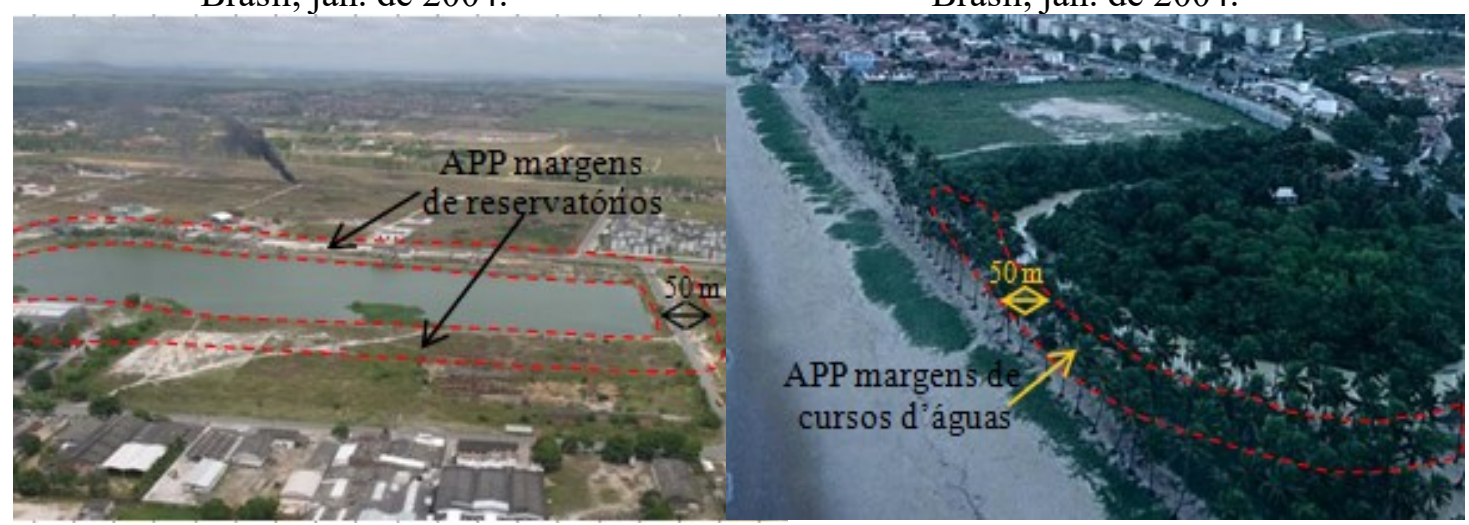

Fonte: Gersrad - Ufal (2003).
Figura 3. APPs margens de rios e nascentes utilizadas por pastagens. Próximo a Riacho Doce - Mun. de Maceió, Alagoas - Brasil, jan. de 2004. 
antrópicas indicados por inúmeros fatos indisciplinares como: a) desmatamentos das encostas para a retirada de madeira deixando os solos (neossolos litólicos, argissolos e latossolos) expostos aos efeitos erosivos ou substituição da mata por cultivos temporários (abacaxi, mandioca e milho); b) o pisoteio do gado (mesmo sendo pastagens rarefeitas) nas médias e baixas declividades das encostas e colinas, facilitando o desprendimento de partículas do solo e transporte de sedimentos, principalmente durante a época chuvosa (agindo a erosividade da chuva associada à fraca resistência do solo, o que acarretará altas taxas de escoamento superficial); c) abertura de segmentos viários em conjuntos de relevo declivosos desprovidos de proteção vegetal e a ocupação desses declives por loteamentos irregulares, não efetivados, como pode ser observado nas APPHs na faixa de expansão urbana de Maceió.

Todos esses fatores causais induzem a processos erosivos nas APPHs traduzidos por escoamentos pluviais (laminar e/ou filetes), ocasionando efeitos de remoção do horizonte $\mathrm{O}$ e $\mathrm{B}$, seja por ravinamentos ou por voçorocamentos, dependendo das condicionantes naturais externas as encostas (declividade, textura, estrutura rochosa e ocupação) e as de subsuperfície (proximidade do lençol freático, coesão das partículas, extratos de relativa impermeabilidade, entre outros).

Acresce ainda que, em função de suas propriedades físicas (absorção d'água, permeabilidade, porosidade, entre outros) os solos ocupados/usados ou sem cobertura vegetal das APPHs serão mais ou menos vulneráveis à erosão. Essa resistência do solo em ser transportado vai depender da sua proteção natural e/ou manejo de usos adequados (práticas preservacionistas e conservacionistas).

\section{CONCLUSÃO}

O uso da terra nas Áreas de Preservação Permanente Hídricas (APPHs) pode ser considerada justificável, partindo do pressuposto que grande parte dessas ocorreu anterior à publicação do Código Florestal Brasileiro Lei Federal n. 4.771 de 15/09/1965 e Resoluções do Conselho Nacional do Meio Ambiente - Conama n. 004/1985 e n. 303/2002. Por outro lado, é injustificável o uso da terra nas APPHs que ocorreu posterior a publicação da referida lei. Esse fato vem apenas confirmar, descompromisso do poder público municipal, que não dispõe de um plano de ação integrado que sirva como referencial no gerenciamento das APPs, em especial nas APPHs.

Os resultados obtidos nesta pesquisa mostram a incongruência do uso da terra x APPHs no município de Maceió. Essa condição tem causado transformações que tem comprometido a estabilidade ambiental e o equilíbrio ecológico, fazendo com que seja necessária, a intervenção do poder público sobre as APPHs e seu entorno a partir de um conjunto de ações voltadas para a gestão/planejamento do seu território.

A partir dos mapeamentos pode-se constatar a necessidade da efetivação de um plano de monitoramento para o município de Maceió por parte dos seus órgãos competentes. Dessa forma, seria possível atenuar e minimizar o uso da terra nas APPHs com a sua reapropriação e recuperação/revitalização, revertendo assim, os impactos ambientais existentes.

A incongruência do uso da terra nas APPHs, evidenciam a ausência e/ou mal planejamento no tocante a proteção ambiental do município de Maceió. Diante deste quadro, urge a necessidade de estudos no sentido de identificar, correlacionar e avaliar os impactos ambientais da ocupação humana, com base nas potencialidades e limitações das APPs, em função das suas características geoambientais (clima, relevo, solo e vegetação).

Diante do quadro atual de transformações porque passa o município de Maceió, o geoprocessamento se mostrou como uma ferramenta eficaz é imprescindível ao (re) conhecimento do uso da terra nas APPHs, possibilitando a verificação das condições supracitadas. 


\section{REFERÊNCIAS}

ALAGOAS, Governo do Estado de Alagoas. Secretaria de Planejamento, Coordenação do Meio Ambiente. Estudo, enquadramento e classificação de bacias hidrográficas de Alagoas. Ricardo Sarmento Tenório e Dilton Brandão de Almeida (Orgs.). Maceió: CONVÊNIO SEMA/SUDENE/GOVERNO DO ESTADO DE ALAGOAS, 1979. 381p.

ALAGOAS, Governo do Estado de Alagoas, SEPLAN, Secretaria de Planejamento, CDCT, Coordenação de Desenvolvimento Científico e Tecnológico, NMRH, Núcleo de Meteorologia e Recursos Hídricos. Relatório da Análise Climática do Estado de Alagoas (Coord. ABREU, R. de A), 1999, $31 \mathrm{f}$. Mimeografado.

ANDRADE, M. C de. Usinas e destilarias das alagoas: uma contribuição ao estudo da produção do espaço. Maceió: EDUFAL, 1997. 134 p.

ASSAD, E. D.; SANO, E. E. Sistema de Informações Geográficas: aplicações na agricultura.Brasília: Embrapa, 1998. 434p.

ASSIS, J. S. Biogeografia e conservação da biodiversidade - projeções para Alagoas. Maceió: Catavento, 2000. 200p.

BERTRAND, G. Paisagem e Geografia Física global - Esboço Metodológico 13. Caderno de Ciências da Terra. São Paulo, Instituto de Geografia, USP, 1972.

BOIN, M. N. . Áreas de Preservação Permanente: Uma visão prática. In: Centro de Apoio Operacional de Urbanismo e Meio Ambiente.(Org.). Manual Prático da promotoria de Justiça do Meio Ambiente. 1 ed. São Paulo: Imprensa Oficial do Estado de São Paulo, 2005, v. 2, p. 849-861.

BRASIL, Ministério da Agricultura Pecuária e Abastecimento, Empresa Brasileira de Pesquisa Agropecuária - Embrapa, Embrapa Solos; ALAGOAS, Secretaria de Estado da Agricultura e Desenvolvimento Agrário, Governo do Estado de Alagoas. Zoneamento Agroecológico do Estado de Alagoas - SEAGRI-AL. Levantamento de Reconhecimento de Baixa e Média Intensidade dos Solos do Estado de Alagoas, Relatório Técnico. Convênios SEAGRI-AL/Embrapa Solos Nos 10200.04/0126-6 e 10200.09/0134-5. Recife: Embrapa Solos, 2012, 238p. 1 DVD-ROM

BRASIL. Lei Federal no 4771/65, de 15 de setembro de 1965, Presidência da República, Institui o novo Código Florestal. Brasília, DF: Congresso Nacional, 1965.

BRASIL. Lei Federal n ${ }^{\circ}$ 4771/65, de 15 de setembro de 1965, alterada pela Medida Provisória $n^{\circ} 2.166$ 67, de 24 de agosto de 2001. Brasília, DF: Congresso Nacional, 2001.

Resolução CONAMA No 004/1985 - "Dispõe sobre definições e conceitos sobre Reservas Ecológicas". Data da legislação: 18/09/1985 - Publicação DOU, de 20/01/1986, págs. 1095-1096 - Alterada pela Resolução nº 10, de 1993. Revogada pela Resolução n 303, de 2002.

Resolução CONAMA No 303/2002 - "Dispõe sobre parâmetros, definições e limites de Áreas de Preservação Permanente". - Data da legislação: 20/03/2002 - Publicação DOU no 090, de 13/05/2002, pág. 068 - Revoga a Resolução nº 04, de 1985. Alterada pela Resolução nº 341, de 2003.

Resolução CONAMA No 302/2002 - "Dispõe sobre os parâmetros, definições e limites de Áreas de Preservação Permanente de reservatórios artificiais e o regime de uso do entorno" - Data da legislação: 20/03/2002 - Publicação DOU nº 090, de 13/05/2002, págs. 67-68

BRASIL. Presidência da República, Casa Civil, Subchefia para Assuntos Jurídicos. Lei n 12.651, de 25 de maio de 2012. Dispõe sobre a proteção da vegetação nativa; altera as Leis nos 6.938, de 31 de agosto de 1981, 9.393, de 19 de dezembro de 1996, e 11.428, de 22 de dezembro de 2006; revoga as Leis nos 4.771, de 15 de setembro de 1965, e 7.754, de 14 de abril de 1989, e a Medida Provisória no 2.166-67, de 24 de agosto de 2001; e dá outras providências. Brasília, DF: Congresso Nacional, 2012.

CASSETI, V. Ambiente e apropriação do relevo. São Paulo: Contexto, 2 ed.. 1995. 147p. CORRÊA, R. L. Região e organização espacial. 7 ed. São Paulo: Ática, 2000. 51p.

COSTA, T. C. C. et al.. Delimitação e caracterização de áreas de preservação permanente, por meio de um sistema de informações geográficas (SIG). Anais... VIII Simpósio Brasileiro de Sensoriamento Remoto, Salvador, Brasil, 14-19 abril 1996, INPE, p. 121-127. 
DANTAS, J.R.A.; CALHEIROS, M. E. de V. Estratigrafia e Geotecnia. In: BRASIL DEPARTAMENTO NACIONAL DE PRODUÇÃO MINERAL. (Mapa Geológico do Estado de Alagoas. Texto Explicativo. Séries Mapas e cartas de síntese, n. 02, secção geológica, n. 02). Recife: Brasil - Departamento Nacional de Produção Mineral, 1986. 8-90 pp. 1 Mapa, color., $90 x 110$ cm. Escala 1:250.000.

FEIJÓ, F. J. Bacia de Sergipe Alagoas. Rio de Janeiro. Geociências: Revista da PETROBRÁS, Rio de Janeiro, 8(1): 149 - 161, jan./mar., 1994.

FLORENZANO, T. G. Imagens de satélite para estudos ambientais. São Paulo: Oficina de textos, 2002. 97p.

FONSECA, A. L. B. de AZEVEDO, L. M. P. Climatologia. In: BRASIL, MINISTÉRIO DAS MINAS E ENERGIA, SECRETARIA GERAL, PROJETO RADAMBRASIL. Folhas SC. 24/25 Aracaju/Recife. Rio de Janeiro: PROJETO RADAMBRASIL, 1983 p. 812-837 (Série: LRN. V. 30).

GARCIA, G. J. Sensoriamento remoto: princípios e interpretação de imagens. São Paulo: Nobel, 1986. 357p.

GAVA, A. et al. Geologia: Mapeamento regional. In: BRASIL, MINISTÉRIO DAS MINAS E ENERGIA, SECRETARIA GERAL, PROJETO RADAMBRASIL. Folhas SC. 24/25 Aracaju/Recife. Rio de Janeiro: 1983. p. 27-252 (Série: LRN. V. 30).

GOES, M. H. de B. Ambientes costeiros do estado de Alagoas. 3 v. Rio de Janeiro, 1979, $397 \mathrm{f}$. Dissertação (Mestrado em Geografia) - Universidade Federal do Rio de Janeiro, 1979.

GOES, M. H. de B. Diagnóstico ambiental por geoprocessamento do município de Itaguaí (RJ). Rio Claro, 1994. 529f. Tese (Doutorado em Ciências - Organização do Espaço) - Universidade Estadual Paulista Júlio Mesquita Filho.

GONÇALVES, L.M.C.; ORLANDI, R.P. Vegetação: as regiões fitoecológicas, sua natureza e seus recursos econômicos - estudo fitogeográfico. In: BRASIL, MINISTÉRIO DAS MINAS E ENERGIA, SECRETARIA GERAL, PROJETO RADAMBRASIL. Folhas SC. 24/25 Aracaju/Recife. Rio de Janeiro, 1983. p. 573-652. (Série: LRN. V. 30).

IBGE, Instituto Brasileiro de Geografia e Estatística. Cartas Topográficas da Região Nordeste do Brasil, Folhas: Pilar SC.25-V-C-IV-1, MI-1600-1, Maceió SC.25-V-C-IV-2, MI-1600-2, Rio Largo SC.25-V-CI-3, MI-1525-3, São Luiz do Quitunde SC.25-V-C-I-4, MI-1525-4. Brasília: IBGE, 1985/1987. 4 Carta, color., $62,5 \times 75 \mathrm{~cm}$ em meio analógico papel impresso e digital imagem jpg 150 dpi e vetorial shp. Escala 1:50.000. Acervo: LGA-IGDema-Ufal.

IBGE, Instituto Brasileiro de Geografia e Estatística. Mapa Municipal Estatístico de Maceió-AL - 2704302. 1. 1 Mapa, Color em meio digital. Malha Territorial 2010, edição 7/24/2011. Nome: arquivo_v2, tipo: Adobe Acrobat Documente (.pdf), Tamanho: 1,77 MB. E= 1:100.000. Rio de Janeiro: CCAR-CETECDDI-IBGE, 2010. Disponível em: <http://goo.gl/pmmWGr>. Acesso em: 28 de jul. 2011.

IBGE, Fundação Instituto Brasileiro de Geografia e Estatística, Banco de Dados Agregados, Censo Demográfico e Contagem da população, disponível em: <goo.gl/VNhoq5>. Acesso em 05 de nov. 2011

IBGE, Fundação Instituto Brasileiro de Geografia e Estatística, Censo Demográfico: 2010. Rio de Janeiro, 2011. Disponível em: <goo.gl/fzJVGv> Acesso em 01 de outubro de 2011.

INPE, Instituto Nacional de Pesquisas Espaciais. Imagem do Satélite Landsat - Sensor TM 5 (Land Remote Sensing Satellite), Sensor TM 5, em formato digital JPG (Joint Picture Expert Group) composição colorida, bandas R3G4B5, com resolução espacial de $30 \mathrm{~m}$, órbita/ponto 214/67, data de passagem 17/03/2011 da NASA (National Aeronauties and Space Administration) - escala aproximada 1:100.000, ampliada para 1:50.000. São José dos Campos: INPE, 2011. Acervo: LGA-IGDema-Ufal

JACOMINE, P. K. T. et al. Levantamento Exploratório: Reconhecimento de solos do Estado de Alagoas. Boletim Técnico e Série Recursos de Solos. Brasil, Empresa Brasileira de Pesquisa Agropecuária; Superintendência de Desenvolvimento do Nordeste, Recife, n. 35, 5, 532 p., 1975.

LIMA, I. F. Ocupação espacial do estado de Alagoas. Maceió: SERGASA S.A., 1992. 160 p. LIMA, I.F. Geografia de Alagoas. 2. ed. São Paulo: Editora do Brasil S/A, 1965. 347 p.

LIMA, W. P.; ZAKIA, M. J. B. Hidrologia da matas ciliares. In Rodrigues, R. R.; LEITÃOFILHO, H. F. (Ed.). Matas ciliares: conservação e recuperação. São Paulo: Edusp/Fapesp, 2a Ed., 2004. 320 p.

MACEIÓ, Prefeitura Municipal de Maceió, Secretaria Municipal de Meio Ambiente. Código Municipal de Meio Ambiente. Maceió, ca. 1997, 32p. 
MACEIÓ, Prefeitura Municipal de Maceió. Ortocartas da Base Cartográfica Numérica da Área Urbana e de Expansão Urbana de Maceió. Consórcio Esteio Engenharia de Aerolevantamentos S.A. - Maplan Aerolevantamentos S.A., 1998. Meio analógico papel impresso. Escala aproximada 1:2.000. Maceió: SMCCU-PMM, 1998.

MACEIÓ, Prefeitura Municipal de Maceió. Mapa - Maceió. Escala 1: 35. 000, FL. 01/01. Esteio Engenharia de Aerolevantamentos S.A.; Maplan Aerolevantamentos S.A., s.d. Maceió: Geoprocessamento SMCCU-PMM, ca. 2000. Disponível em: $<\mathrm{http}$ ://semecmaceio.com/mapas/mapadebairros.jpg > . Acesso em 05 de outubro de 2011.

MARTINS, P. T. A. Análise das intervenções antrópicas no manguezal do rio Cachoeira, Ilhéus, Bahia. 2008. Dissertação (Mestrado em Geografia) Núcleo de Pós-Graduação em Geografia, Universidade Federal de Sergipe, 2008.

NASCIMENTO, M.C. do. Mapeamento das Áreas de Preservação Permanente e dos conflitos de uso da terra na bacia hidrográfica do rio Alegre, ES. Viçosa, 2004. 92f. Dissertação (Mestrado em Ciência Florestal) - Universidade Federal de Viçosa.

NASCIMENTO, M. C. et al. Uso do geoprocessamento na identificação de conflito de uso da terra em áreas de preservação permanente na Bacia Hidrográfica do Rio Alegre, Espírito Santo. Ciência Florestal, v. 15, n. 2, p. 207-220, 2005.

NASCIMENTO, M. C. et al., E. Delimitação automática de áreas de preservação permanente (APP) e identificação deconflito de uso da terra na bacia hidrográfica do rio Alegre. In: Anais... XII Simpósio Brasileiro de Sensoriamento Remoto, Goiânia, 2005, INPE, p. 2289-2296.

NOU, E.A.V. et al. Geomorfologia. In: BRASIL, MINISTÉRIO DAS MINAS E ENERGIA, SECRETARIA GERAL, PROJETO RADAMBRASIL. Folhas SC. 24/25 Aracaju/Recife. Rio de Janeiro: DIPUB/RADAMBRASIL, 1983. p. 347-443 (Série: LRN. V. 30).

NOVO, E. M. L. de Moraes. Sensoriamento Remoto. Princípios e Aplicações. 4. ed. São Paulo: Edgard Blucher, 2010. 388p.

PEREIRA, M. N., et al.. Cobertura e uso da terra através de sensoriamento remoto. São José dos Campos: Presidência da República, Secretaria Especial da Ciência e Tecnologia, Instituto de Pesquisas Espaciais - INPE, 1989. 118p. (INPE-5032-MD/0420).

RIBEIRO, C. A. A. S. et al. O desafio da delimitação de áreas de preservação permanente. Revista Árvore, Viçosa, 29, 2:203-212, 2005.

SALES, V. de C. “Geografia, Sistemas e Análise Ambiental: Abordagem Crítica”. Geousp - Espaço e Tempo, São Paulo, n. 16, p. 125-141, 2004.

SANTOS, M. A natureza do espaço: técnia e tempo, razão e emoção. São Paulo: Hucitec, 1996. 308p.

WAKE. M.; et al.. Pedologia: levantamento exploratório de solos. In: BRASIL, MINISTÉRIO DAS MINAS E ENERGIA, SECRETARIA GERAL, PROJETO RADAMBRASIL. Folhas SC. 24/25 Aracajú. Rio de Janeiro: DIPUB/RADAMBRASIL, 1983. p. 445-572 (Série: LRN. V. 30).

XAVIER DA SILVA, J. Geoprocessamento para análise ambiental. Rio de Janeiro: J. Xavier da Silva, 2001. 228p.

ZANATTA, F. A. S.; LEAL, A. C. Análise ambiental das áreas de preservação permanente no médio curso do rio Paranapanema. In: XIII Simpósio Nacional de Geografia Física Aplicada. 2009, Viçosa- MG. Trabalhos completos, Eixo 03... Viçosa-MG: Universidade Federal de Viçosa, 2009, 13p. 


\section{APÊNDICE A. MAPA DE USO DA TERRA/COBERTURA VEGETAL - MUNICÍPIO DE MACEIÓ} - ALAGOAS - BRASIL

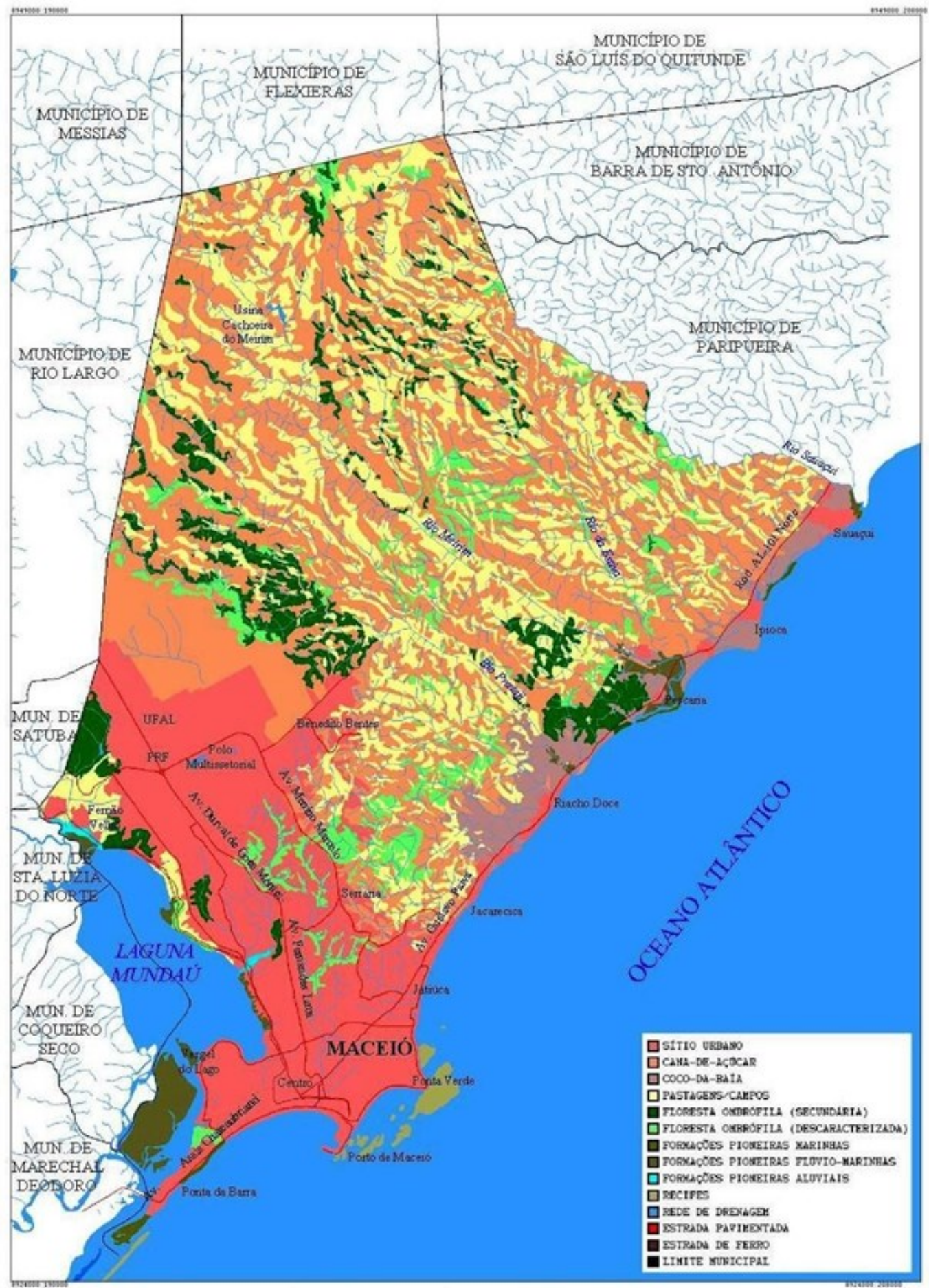

Elaboração: Sinval Autran Mendes Guimarães Júnior, nov. de 2011. Fonte: INPE (2011); IBGE (1985/1987). 
APÊNDICE B. MAPA DE ÁREAS DE PRESERVAÇÃO PERMANENTE HÍDRICAS - MUNICÍPIO DE MACEIÓ - ALAGOAS - BRASIL

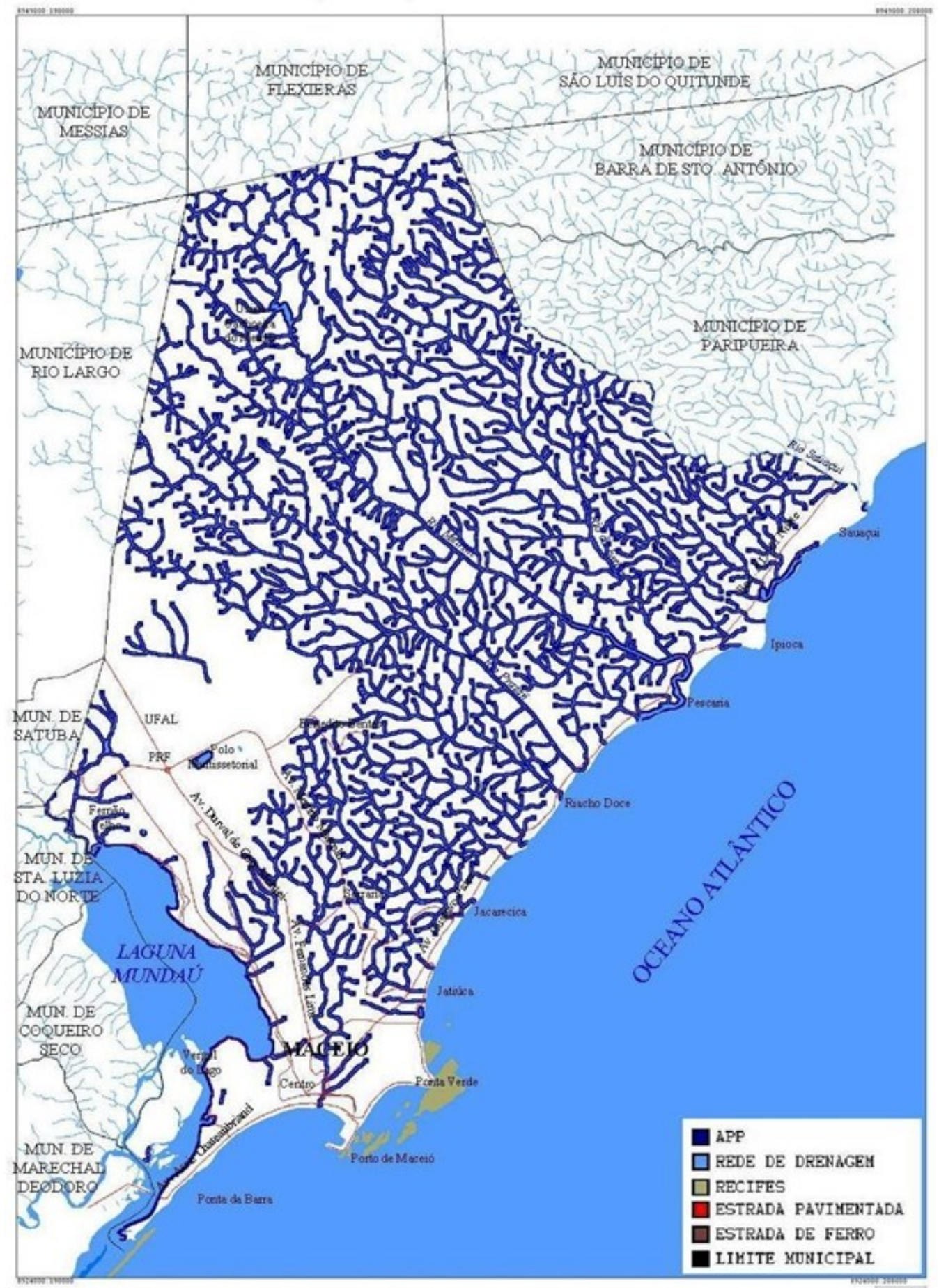

Elaboração: Sinval Autran Mendes Guimarães Júnior, nov. de 2011. Fonte: INPE (2011); IBGE (1985/1987). 
APÊNDICE C. MAPA DE USO DA TERRA/COBERTURA VEGETAL EM ÁREAS DE PRESERVAÇÃO PERMANENTE HÍDRICAS - MUNICÍPIO DE MACEIÓ - ALAGOAS - BRASIL

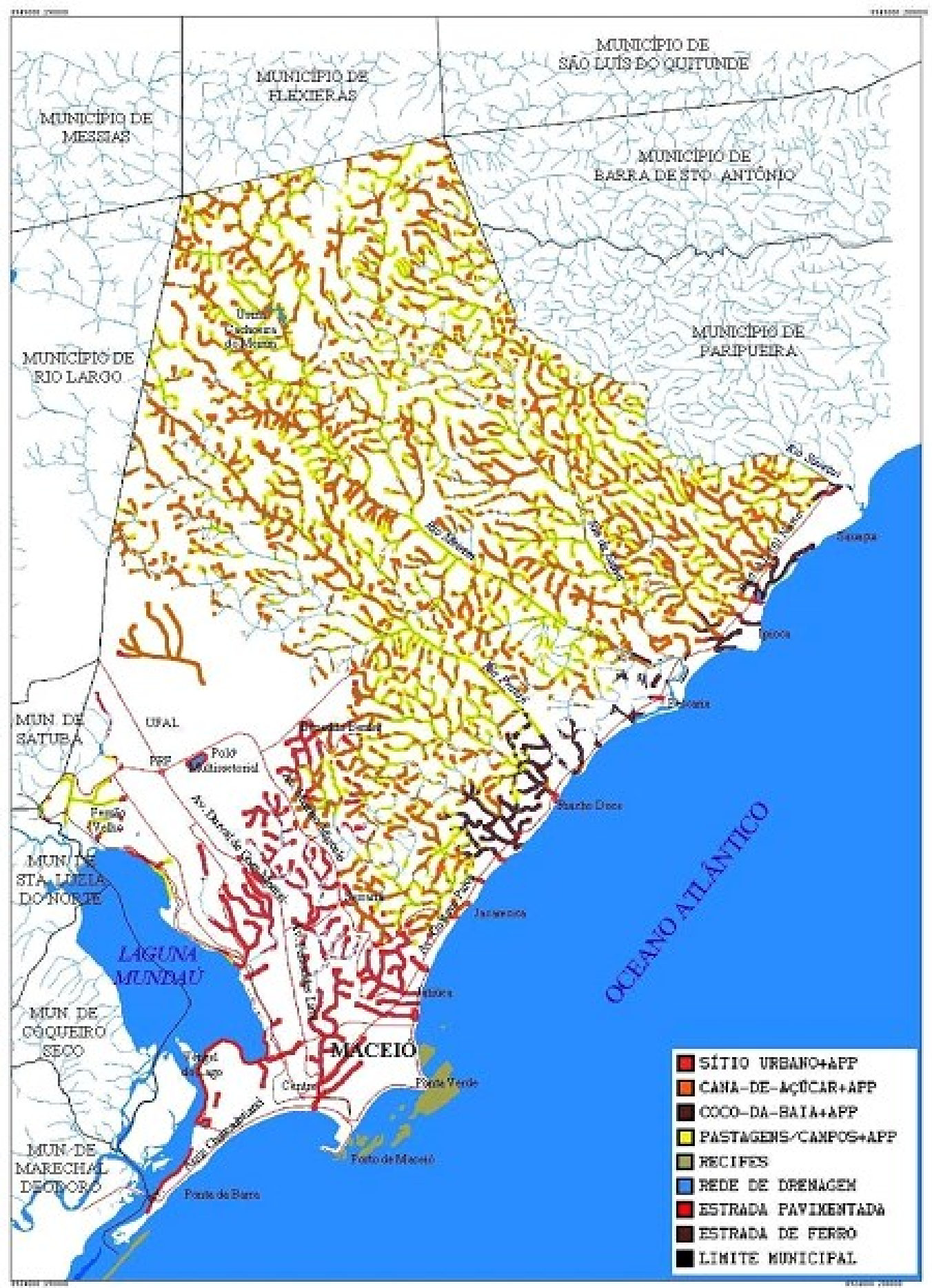

Elaboração: Sinval Autran Mendes Guimarães Júnior, nov. de 2011. Fonte: INPE (2011); IBGE (1985/1987). 


\section{ANEXO A. IMAGEM DO SATÉLITE LANDSAT TM-5}

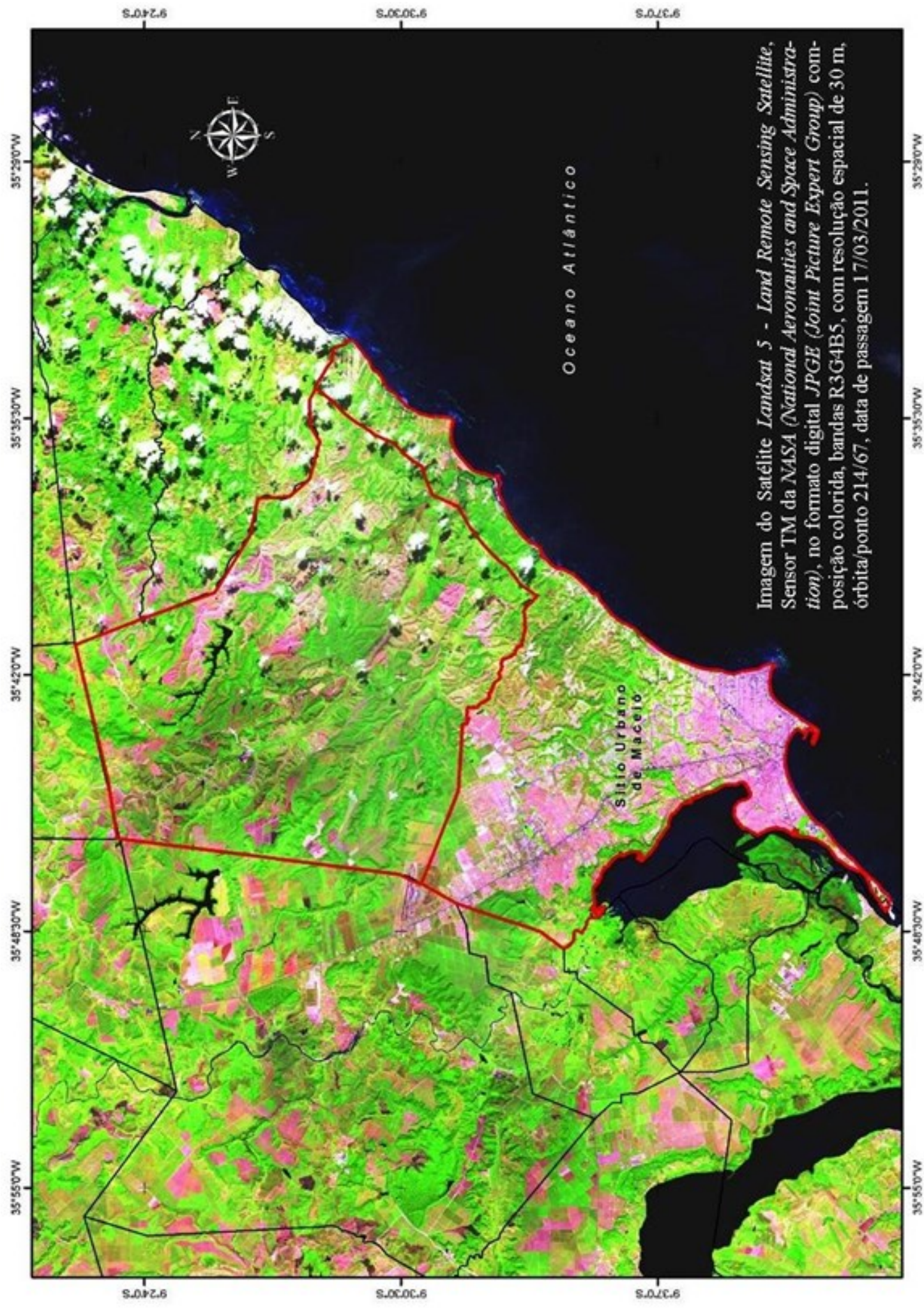

